\title{
Reviews of E-Skills Integration into Society: An Attempt for Deploying E-Skills in South Africa
}

\author{
A.Vasisht \\ Department of Informatics, Tshwane University of Technology, South Africa \\ N. Ruxwana \\ Department of Informatics, Tshwane University of Technology, South Africa \\ Y. Olusanya Agunbiade \\ Department of Informatics, Tshwane University of Technology, South Africa
}

\begin{abstract}
Unemployment is an issue currently receiving attention world-wide, but E-skills which refers to the ability of individuals to create and use all systems of ICT to satisfactorily improve their daily lives have become an important factor to consider in any growing society. It important and contribution towards employability that minimize unemployment in any society as attracted researchers towards focusing on this area. Various techniques for integrating E-skills into the society has been proposed by many researchers with remarkable achievements, but the growing rate of unemployment in South Africa is increasingly becoming very high and a major concern in our society. In the attempt to address this problem, this review was conducted to investigate how E-skills are integrated to different societies, the result attainted and how it could be deployed in South Africa to minimize unemployment.
\end{abstract}

Keywords - e-skills, South Africa, ICT.

\section{INTRODUCTION}

In the literature as related to E-skills, Information Communication Technology (ICT) is an important factor mentioned these researchers [2][3][8][5][10][1][7]. ICT is a brolly term that comprises various communication devices: television, mobile phones, network, computer, software, hardware, satellite and as well as applications [5]. All the component of ICT has become an important tool for making life's easier and contributions to any growing economy most especially for job creation [5]. Unemployment appears to be very low in South Africa during the 1970 s and 1980 s but recently the situation has changed, a national survey conducted shows that before 1994 the unemployment rate was at $13 \%$, but by the end of the decade the unemployment rate had increased to almost 30\% [4], and this as not only affected individuals but also the economy of the society. Beside what the government is doing to address this issue, there are steps that needs to be taking by individuals and organizations to reduce unemployment in the society. However several researchers have proposed the integration of E-skills into the society to reduce unemployment. Since South Africa is also struggling with unemployment, that needs to be provided with a solution, it is important to study deep into the recent past of various researcher work to understand the changes that have taken place in this research area (E-skills method) and to also come to a conclusion as to what more needs to be done toward unemployment in our society. The review of the methodologies of these researchers will help in making right decision of whether to adopt, or create, or propose a new method of integrating E-skills into our society.

\section{LITERATURE REVIEW}

As the rate of unemployment is growing, it has become a concern worldwide and E-skills have become a significant study attracting the attention of researchers because of it support towards employability with an effect that can reduce unemployment. Various technique of integrating E-skills into the society has been proposed by various researchers with outstanding result achieved. This section reviews some of the work implemented by these researchers, their techniques and the limitations they encounter during the execution of their methods. 
In the work of [2], it was stated that E-skills development is an important aspect of any national development and adopting it into the society will develop Uganda economy. Their strategic technique of implementing Eskills into Uganda is from a lesson learnt from South Korea Republic. South Korea Republic journey into an advanced setting of ICT society started in the 1980s [2], their main focus target improve infrastructure and government services for Korean citizen and to become a society with advance ICT. The implementation of their technique is based on a project called National Basic Information System (NBIS). The Project is carried out in two stages; the first stage was carried out in 1987-1991. They attempted to establish a major database for government work related to residents, financial service and land. The second stage was carried out in 1992-1996 with a focus that targeted inter connection of government parastatal so that administrative information could be shared easily. These two steps contributed a lot of advancement and improvement which further lead to rapid growth in Korea economy and level of information most especially between government workers. Although these was a major development in the society but the survey conducted in 2000 showed that the level of internet and computer use by physically disabled, farmers, fisherman and house wife is low than other social groups like government employees. The survey also revealed the widen gap increase between the two set of groups as the disadvantage people were reluctant to learn or improve on ICT, and this made the government to Implement a policy that will favoured them. They taught us making the facilities available. The government ensured to build broadband infrastructure that is fully equipped and functional. Various facilities like school, Military unit and post offices are used as centres for training this people. The main purpose of training this people it to enhance their ability to search and utilize information related to their daily life's that will make them productive, and these will not only help them to grow personally but it will also improve the overall economy growth of their country because poverty will be reduced.

The research work of [3]is based on ICT skills and employment. The aim of the research is to measure the impact that E-skills has on the labour market of two cities in Latin-America: Buenos Aires and Bogota. In their work they acknowledged ICT to be a widely resources for socio economic development. They also emphasis on the new era of ICT providing developed countries with the opportunity of meeting vital goals such as health care, poverty alleviation, military and others. But they are not aware about the important of e-skills and it relevant role in increasing employability. They try to put it to test to see the effectiveness of E-skills towards employability and they focus particularly on the labour market because they will be able to monitor the trend of people getting employment. In carrying out there experiment, several fictitious CVs were sent to real job vacancies. The variables included in the CVs are similar except for sex and E-skills level of various applicants, and sending various CVs, it is measured to see whether the numbers of e-mail or call-backs for interviews received by the E-skills applicant is widely different from those received by the E-unskilled applicants. The experiment was carried out in Buenos Aires and Bogota with cross-sectional sample of 11,000 CVs sent across two occupational categories: Sales/Commercial and Administration/accountancy. They find out that applicant with high level E-skills on their CVs significantly increases their chance of being called for an interview than applicant with low or no E-skills. In this type of result attained, they suggested that individuals should improve their E-skills because it will further enhance their chance of getting employed in Latin America. In conclusion, the result achieved shows the important of E-skills and support E-skills ability to increase employability.

In the research of [8] emphasis on the important of E-skills by revealing the study conducted by Australian government in 2002. The department of Australia chamber of commerce and industries conducted a study that reveals that employers tends to seek for series of personal attributes in skills and technical knowledge, this attribute are known as employability skills, it is not only required to gain employment but will also help to progress with an organisation so as to attain ones potential and contribute successfully to the goal of the organisation. However, not everybody in Australia is making use of the fact revealed by the department of Australia chamber for commerce and industry to their advantage. Their study of reveal that almost all the student enrolled for the coursework master's degree offered in the University of Wollongong, Faculty of informatics are international student and majority of these student are willing to stay in Australia after graduating from the university. The study further reveal that finding professional job in Australia is difficulty for these graduates that are international student and this is as a result of their lack of employability skills within the Australia labour market. In an attempt to address the problem faced by international student, they proposed to include employability skills in ICT master's course work curriculum. They decided not to focus on international student doing undergraduate because there is sufficient opportunity and time to work toward accomplishing these qualities, but post graduate coursework programs are relatively obtained over short period of time. In implementing their ideas, they decided to create a subject for the degree that will focus on improving the employability skills of the student. In order to measure student satisfaction and achievement, an evaluation was conducted for feedback from 38 students that completed the survey and the result are as follows: $78 \%$ either agree or strongly agree they have learn a lot about Australia culture, 89\% agree or strongly agree they feel integrated in Australia life and more competent of getting employment. They are also confident in using English 
language to their advantage and this has massively improved employability for international student in Australia.

The work of [5] proposed E-skills has a fundamental skills for every workers beyond ICT sectors and advised lower skills and lower wage workers to acquire E-skill training to enhance their employability. Figure 1 shows the relationship between E-skills training and employability concept map.

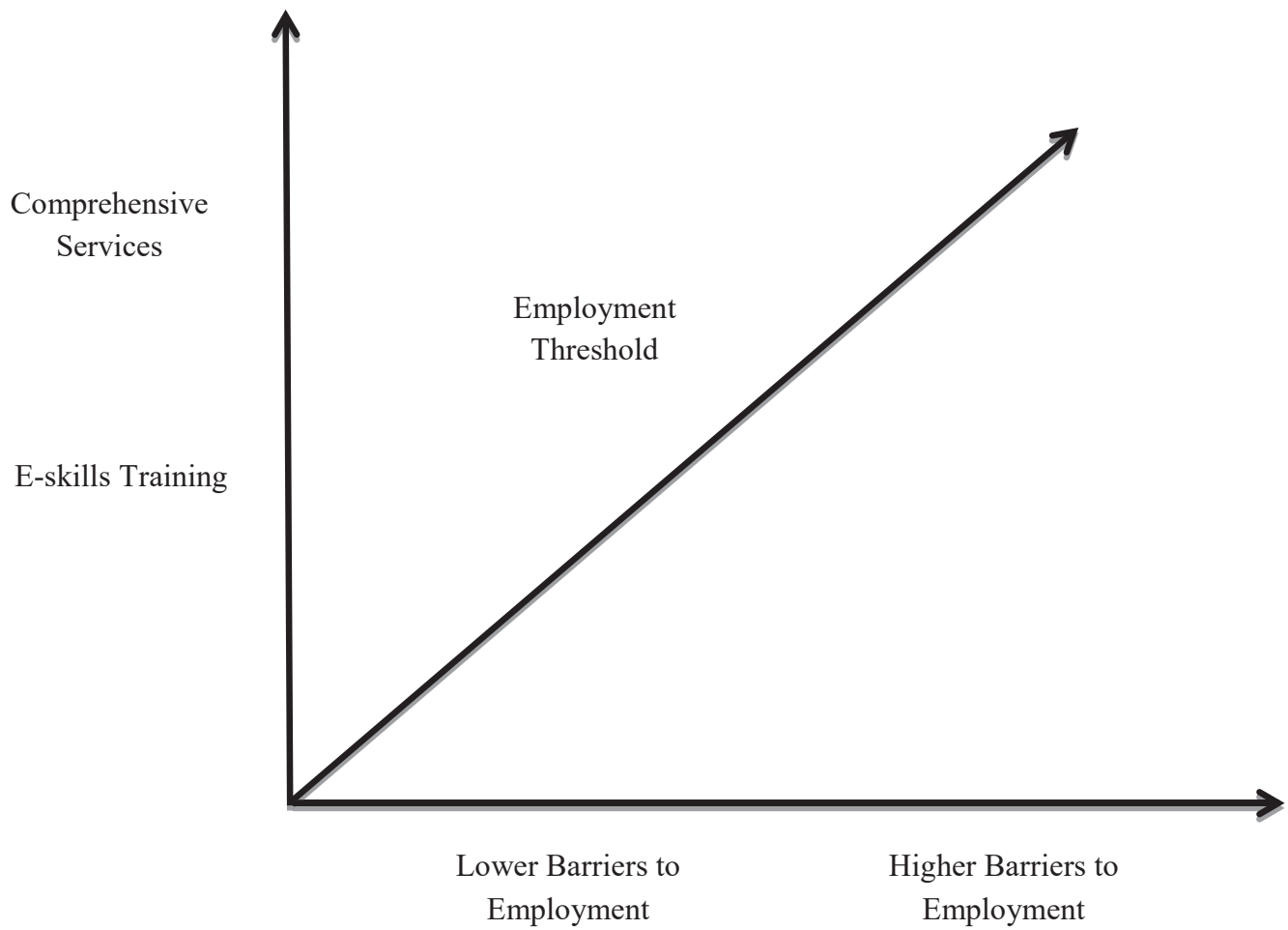

Figure 1. E-skills Training and Employability Map

In acquiring E-skills to enhance employability for lower wage and lower skills workers, they proposed the use of Community Based Organization for integrating E-skills into the society because they are important intermediaries to provide skills and knowledge that reduce unemployment among disadvantaged populations and utilize their network of service provider to improve employability for lower skill and lower wage workers in the United States of America. To validate their study, experiment was carried out by targeting community based organization that provide E-skills training and for which employability is also their main objective. Eight community based training community based organizations were deeply interviewed, more than 40 interview are conducted with service provider and 46 survey responses from 19 different state, all these were conducted in the United State of America. The results from the analysis is very impressive and also reveal the important of community based organization program that provide E-skills to their trainee, as it can facilitate employment for their trainee and create pool of reliable workers that will be productive to any organization.

In the research of [10] they review several studies that established the effect and relationship of E-skills on employability. Furthermore, they reveal how businesses and practices of enterprises across all sectors of the economy have been transformed by ICT. They also revealed the new skills that are needed to exploit new innovation and technology taking place in the labour market of today. Been aware of the important of E-skills from previous research, they focus their attention on Technical and vocal Education. Their study reveal the challenges facing the graduate of technical and vocal education because they are unemployed in the society, and these graduate are from an institute globally accepted for providing trained graduate for industrial, commercial and agricultural development. The cause for this unemployment is that technical and vocal education graduate still need to be more updated in E-skills advancement that will enable them handle tools, machineries and applications that are ICT operated which are recently developed as a result of advancement in technology and they plan to address this issue by introducing E-skills into the curriculum of technical and vocal education Institute. Figure 2 shows the requirement in producing E-skilled technical and vocal education graduate. 


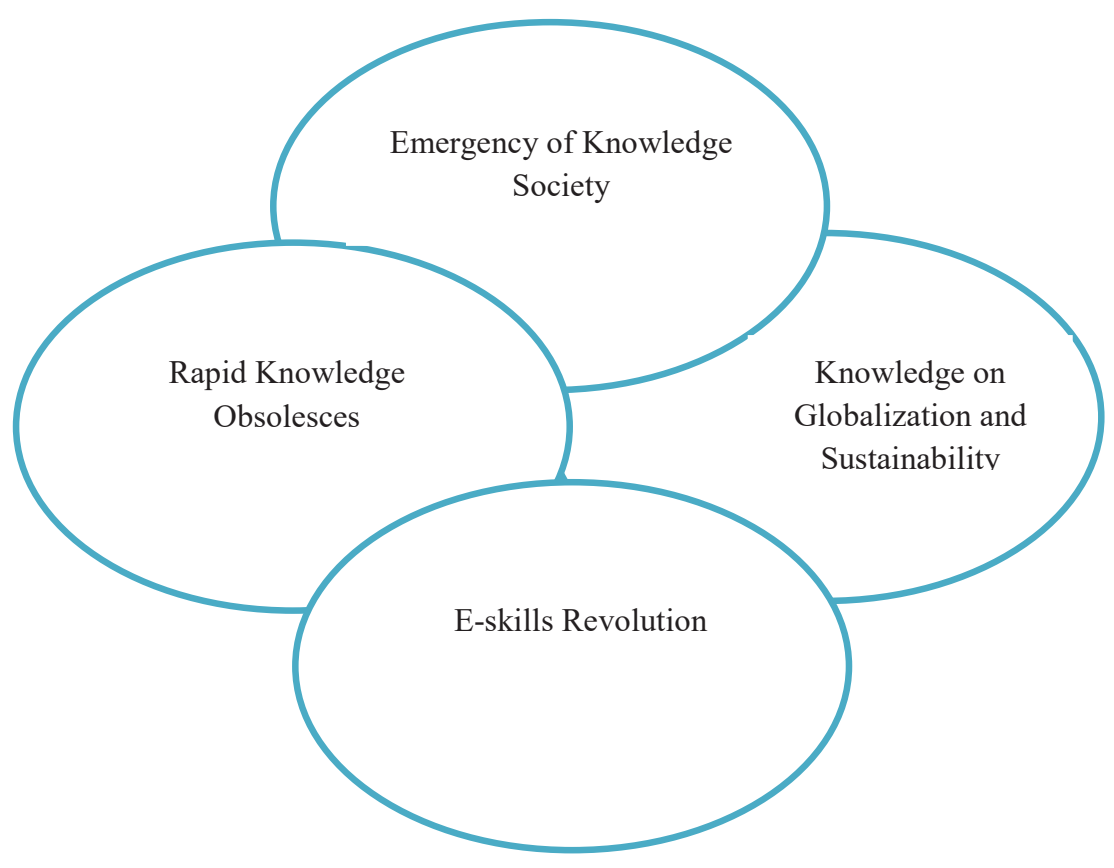

Figure 2. Requirement in producing E-skills TVE graduate

Experimental result after implementing their technique looks impressive and encourages other technical and vocal education in training graduate that are empowered with varieties of E-skills that will improve their employability and enable them compete favourably in the labour market for employment.

The work of [1] targeted ICT graduate in Ghana. In their work they mention what happen in the past years when there was a tendency of companies employing fresh graduate from the university to work for them in their organization without the need of acquiring additional skills or training because tertiary institute as they were satisfy the need of the companies. But in recent time, there has been a tremendous negative shift leading to a growing concern of unemployment in university graduate including graduate student from ICT. Their study also revealed that this issue is not only persisted in Ghana but in order Sub-Sahara Africa country like Nigeria. In attempt to address this issue, they provide more clarity to various challenges of Unemployment for ICT graduate in sub-Saharan Africa but focusing their attention on Ghana. Some of the challenges they mentioned is in the area of education facilities. The educational experience in Europe and other developed countries shows that engineer and scientist are given funding either by government or Non-governmental organization to support high interest area in technology and area. This has resulted to a challenge to those countries tertiary institutions to provide the required innovations that they need to industrialize those countries in the area to technology that will end up enhancing graduate employability. But this type of funding is not in place in Ghana. Another challenge they mentioned is in the area of enrolment criterion. Most tertiary institution that offer ICT programs needs to clear cut strategies to produce quality skilled graduate specialized in specific areas, but institution in Ghana and some other Sub-Sahara African countries provide graduate with general skills and training, producing graduate with lack of speciality making them unemployable. Apart from the above mentioned challenges, many more challenges of ICT graduate unemployment are mentioned, but in overcoming them all they postulated several modules into the curriculum of the programs that will improve their skills and the level of the graduate competency and also the focus which universities must emphasized on.

In the work of [5], they argued that basic E-skills are essential but might not be sufficient enough for some disadvantage population to enhance their employment status. The changing skills demands on today labour market and the role ICT plays across industrial and economic sector, and how it can improve employment opportunity for low-income people have been a subject of discussion for intellectuals. Researcher like the technology and social change group of the University of Washington has been investigating for the past four years the relationship between ICT skills and employability. The research work of the Technology and Social Change (TASCHA) group also looks into the relationship of ICT and employability and similar to their study but they are proposing an analytical framework to better understand the role of ICT skills towards improving employability for low income people. Their study considers some important factor to develop their framework. These factors are as follows: 
NGOs: this play a very important role of advocating for low worker and disadvantage population and stand as intermediaries between this group and labour market.

Another factor considered to build the framework is:

The history, experience and asset of the people who are actually looking for a job has a direct impact on their employability.

The last factor considered to develop the framework is:

The environmental factors: community dimension and social dynamic also have influence on employability.

All these factors put together play a major role in understanding the relation between E-skills training and employability.

Experimental performance of the analytical framework presented in their study is used to analyse the contribution of ICT training to the employability taking into account immigrant woman in the European Union. In summary, experimental results shows that the more advance in ICT skills these women are the higher their chances of employability in European Union. Therefore it is advice to be empowered with advance E-skills to facilitate employability's.

The work of [7], is the most important study of all the related work mentioned earlier, although they all support the important of E-skills but their attention is focused mainly on their countries and economies. The cause for Eskills challenges varies for different countries depending on their level of civilization [6], but the research of [7]focus mainly on South Africa. In their study they didn't only reveal the challenges of ICT skills requirement but also proposed various solutions to address the issue in South Africa. Their study emphasis that South Africa is also experiencing E-skills shortage but to what extent is the shortage and nature of the skills needed is difficult to establish. Their research looks at the causes for these and tries to establish a fact towards skills shortage by undertaking a systematic and comprehensive collection of various types of document which includes new reports, official report, formal report and usually extensive report. Some of these documents are publicly available and other documents were collected by demanding for copies of privately commission report. Also international report was used to provide fair evaluation and comparison, most of the document and material used focus specifically on South Africa and are all listed in their bibliography. In summary, the outcome from the evaluation and comparison shows that there is truly E-skills shortage in South Africa and it also reveal that the government agencies and political leaders are aware of it, and they have been trying to improve on E-skills shortage by carrying out some relevant steps. One of the step carried out is the explicitly including ICT into several pieces of legislation and policies. Sector Education and Training Authorise was established in March 2000 to regulate the information system electronics and telecommunication technologies sector. The major reason why the government is carrying out these tasks is to maximize the potential of ICT sector in contributing to Job creation and generation. The other step carried out is the creation of advisor committee such as President International Advisory on Information Society and Development (PIAC on ISAD) was established in 2001 to stimulate the growth of ICT sector. One of the proposals that was reviewed and accepted by the government and President International Advisory on Information Society and Development (PIAC on ISAD) is the creation of universities or higher education institutes that will only focus on ICT education and training, examples of this institute is Meraka E-skills Institute. But this type of institute can only provide E-skills facilities for few people.

\section{CONCLUSION}

After conducting the review study, in an attempt to introduce E-skills into the society, since it is obvious that there is E-skills shortage in South Africa. We will be focusing our attention on how to increase on the number of graduate equipped with E-skills since unemployment is also ravaging among graduate. However, in the future work, we will be proposing to develop a model to integrate E-skills into the curriculum of every tertiary institution in South Africa, since the major way of producing this graduate into labour market is through tertiary institution, therefore successfully integrating E-skills into the curriculum of every tertiary institute will enhance graduate employability because has individuals are graduating they are already equipped with adequate E-skills that will facilitate their employment in the labour market. This will not only improve South Africa economy in terms of productivity, it well help to deliver quality care for their citizen while it also reduces unemployment generally in the country. 


\section{REFERENCES}

[1] Edward Danso Asong, Emmauel, A. Affum \& James B. Hayfron-Acquah, The Challenges of ICT Graduate Un-Employment in Developing Economies in Africa - Case Study: Ghana. International Journal of Computer Science and Network (IJCSN), vol 2 (12), Issue3, June, 2012.

[2] Asio Evelyn Patra, Developing National E-skills in Uganda: Lesson learnt from Korea and South Africa. Global Information and Communications Technology Program: School of innovation:pp 1-41, January 2013.

[3] Mariana Blanco \& Lopez Boo Florencia, ICT Skills and Employment: A Randomized Experiment. Institute for the Study of Labor (IZA). IZA Disscusion Paper No: 5336:pp 1-18, November 2010.

[4] Taryn Dinkelman. The Effects of Rural Eletrification on Employment: New Evidence from South Africa. The American Economic Association, Vol 101, No 7:pp 3078-3108, November 2011.

[5] Maria Garrido, Joe Sullivan \& Andrew Gordon. Understanding the Links Between ICT Skills Training and Employability: An Analytical Framework. Published Under Creative Commons Atrribution-Non Commercial-Shared alike 3.0 unported License, vol 8 No:2 pp17-32, 2012.

[6] Gabriel Kabanda. The Impact of ICTs on Innovative Sustainable Development in East and Southern Africa. Zimbabwe Open University, Harare, www.researchgate.net/publication/2248300081. DOI: 0.5772/36467, April 2012.

[7] Hugo H. Lotriet, Mactheld. C. Matthee \& Patricia M Alexander Challenges in Ascertaining ICT Skills Requirements in South Africa. South African Computer Journal (SACJ), University of Pretoria, Lynnwood Rd, Hatfield, December 2010.

[8] Fazel Naghdy, Alison Hayes \& Emily Purser Building employability Skills in ICT Master Coursework Curriculum. Australasian Association for Engineering Education, ISBN1 876346 59 0:pp 668-672, December 2009.

[9] Robert J. Shapiro \& Arpana Mathur. The contribution of Information and Communication Technology to American Growth, Productivity, Jobs and Prosperity. Published CiteSeerX, $\underline{\text { http://citeseerx.ist.psu.edu/viewdoc/download;jsessionid=223cf538f1d1723f96c823d26e14a911?doi=10.1.1.5993.4373\&rep=rep } 1 \& \text { typ }}$ e=pdf:pp 1-31, September 2011.

[10] Hassan Bello, Babawuro Shu'aibu, Muhammad Sukri bin Saud and Yahaya Buntat. ICT Skills for Technical and Vocational Education Graduates' Employability. Journal of World Applied Sciences, ISSN 1818-4952, vol 23 (2):pp 204-207, June 2013. 